\title{
A Ambiguidade Homem/Animal em Mal dos Trópicos e a dimensão xamânica da Imagem
} Henrique Codato

\section{Resumo}

Propomos desenvolver algumas reflexões acerca das ambiguidades presentes em Mal dos Trópicos

- mais exatamente sobre a dualidade homem/ animal -, estendendo a discussão para 0 estatuto que a imagem cinematográfica assume em relação à experiência do espectador de cinema em nossos dias. A obra de Weerasethakul torna-se exemplar para pensarmos o cinema contemporâneo, uma arte em constante transformação, que se abre para a alteridade, para 0 "devir-outro", revelando, com isso, outras formas de espaço e de temporalidade, novas relações de identidade e de diferença.

\section{Palavras-Chave}

Cinema. Weerasethakul. Ambiguidade. Imagem. Alteridade.
Henrique Codato I picega@hotmail.com Doutor em Comunicação Social pela Universidade Federal de Minas Gerais (UFMG). Pós-doutorando em Comunicação pela Universidade Federal do Ceará (UFC).

\section{Introdução}

Talvez tenha se tornado um tanto consensual classificarmos os filmes de Apichatpong Weerasethakul como produções de um cinema dito "transcultural", "de fluxo $0^{2 "}$ ou, ainda, "de sutilezas ${ }^{3}$ ". Longe de qualquer tentativa de generalização ou sistematização - sem, no entanto, querer desvalorizar ou diminuir esses esforços agregadores -, é preciso reconhecer que 0 diretor tailandês produz um tipo bastante particular de cinema, de extremo apelo sinestésico, buscando explorar, na articulação entre imagem e som, uma dimensão muito mais sensorial que racional, atravessada, sem dúvida, por algo da ordem do espiritual. Desse modo, ele reinsere os corpos filmados "num espaço-tempo concebido como duração e experiência, ou seja, como desencadeador de afetos" (VIEIRA JR., 2009, p. 01).

Dominique Païni (2010, p. 18) afirma que tais afetos dizem respeito tanto "a um estado físico que reúne prazer e dor", quanto "a um processo mórbido que vem colocar o corpo em perig $0^{5 "}$. Mas 
que risco seria esse? 0 que parece tão ameaçador no cinema de Weerasethakul? Para Païni (2010), os corpos tocados pela câmera do cineasta se reduzem a "epidermes", ao passo que os planos por ela construídos se convertem em "superfícies sensoriais". Com efeito, os corpos filmados pelo diretor parecem querer apenas deambular, vagar de uma cena para outra; flanar, para nos lembrarmos, aqui, de Walter Benjamin' . À medida que a errância desses corpos avança no tempo da narrativa, o filme, então, tende a deslocar-se para 0 interior de seus personagens, passando a registrar um universo subjetivo, comandado, em larga medida, pelos afetos e pelas paixões.

Toda reunião em torno de uma obra de arte remete-nos a algo da ordem do passional. No cinema, projetar nada mais é do que lançar uma pulsão dirigida à percepção; colocar em movimento uma energia desejante, que tem como princípio convocar o desejo daquele que vê, envolvendo os sujeitos em torno de uma mesma experiência. A tela se torna, nesse sentido, um espaço privilegiado para a encenação das paixões humanas: amor, medo, dor, fascinação. Assim, em um movimento que é duplo, o filme é projetado para 0 espectador e este se projeta no filme; nesse gesto, ele investe seu desejo em troca da experiência de vivenciar o desejo do outro. Como explica Jean-Louis Comolli, "tudo se passa entre 0 filme e mim, nesse entre-dois que é transporte de um no outro: projeção" (COMOLLI, 2008, p.96).

Sublinhamos, nessa perspectiva, a singularidade do olhar que Weerasethakul projeta sobre seu país natal e sua cultura. Os espaços filmados pelo cineasta trazem uma dimensão espiritual que vai além da construção ou da ambientação de quadros e planos, mas que reside em sua maneira peculiar de captar o mundo que 0 cerca e de transformálo em ficção. Maxime Scheinfeigel (2008) aponta uma "tradição animista" no cinema do diretor, herança da cultura Khmer ${ }^{7}$ que ainda subsiste fortemente na Tailândia (principalmente entre os habitantes da zona rural), estabelecendo inúmeros sincretismos com 0 budismo, religião predominante no país. Ainda que fortemente influenciada pela modernidade tecnológica do século 20, a Tailândia

Termo proposto e desenvolvido pelos antropólogos David McDougall e Lucien Taylor em seu livro Transcultural Cinema (Princeton University Press, 1998).

Expressão cunhada pelo crítico francês Stéphane Bouquet na edição de março de 2002 da revista Cahiers du Cinema (n. 566) para referir-se a um tipo de cinema contemporâneo que apresenta narrativas "constituídas a partir de sensações, desdobrando-se num trabalho de câmera capaz de explorar a relação corpo/espaço dentro de uma experiência do tempo como atmosfera" (VIEIRA JR., 2009, p. 03).

Termo lançado por Emmanuel Burdeau na edição de setembro de 2005 da revista Cahiers du Cinéma para classificar uma especificidade relacionada às sensações como a leveza e a delicadeza e que afetaria alguns filmes diretamente em seu dispositivo ficcional, no cerne da narração cinematográfica.

No original: (...) un état physique qui réuni plaisir et douleur. (Nossa tradução). 
vê florescer um culto aos espíritos que as barreiras sociais, culturais ou religiosas parecem não impedir de fazer circular, e que preenche a vida cotidiana de inúmeros tailandeses.

Scheinfeigel (2008) supõe que esse caráter anímico que preenche 0 cotidiano dos tailandeses se encontraria substancialmente presente na arte de Weerasethakul por meio do imbricamento de crenças e de saberes arcaicos colocados em cena e registrados através do dispositivo cinematográfico. A autora reconhece entre eles um mesmo princípio: para ela, tanto a magia quanto o cinema concebem o mundo a partir de sua duplicidade, possibilitando a manifestação de um duplo que é outro, mas, ainda assim, 0 mesmo mundo. Para ela, o cinematógrafo vem fornecer à magia uma "encarnação tecnológica" (SCHEINFEIGEL, 2008, p.163), e, ainda que 0 cinema tenha mudado consideravelmente ao longo de sua existência, ao menos no que tange ao papel do espectador, o pacto parece seguir intocado: a experiência cinematográfica continua a buscar a mesma sensação original de espanto, assombro e surpresa que sacudiu, de partida, os primeiros espectadores de cinema.
Nascido na província de Khon Kaen, no nordeste da Tailândia, Weerasethakul é um dos poucos cineastas tailandeses que trabalham fora do sistema industrial de produção audiovisual que predomina em seu país ${ }^{9}$. Filho de médicos (fato que talvez explique sua obsessão por hospitais e personagens enfermos ${ }^{10}$ ) e arquiteto de formação, ele começou a se dedicar ao cinema no início da década de 1990, ao tornar-se aluno da Escola de Artes de Chicago, nos Estados Unidos. Seu primeiro trabalho a ganhar certa projeção foi Mysterious Object at Noon (Dokfa Nai Meuman, 2000), longa que já traz algumas das características técnicas e estéticas que marcarão seu cinema - uma mistura de ficção e documentário, filmado no campo, sem roteiro convencional, com uma narrativa fragmentada, elaborada a partir de relatos filmados -, seguido de Blissfully Yours (Sud Sanaeha, 2002) e The Adventure of Iron Pussy (Hua Jai Tor Ra Nong, 2003), este último em codireção com outro cineasta tailandês, Michael Shaowanasai.

Mal dos Trópicos (Sud Pralad, 2004), filme que nos interessa de forma precisa neste artigo, foi aclamado pela crítica de cinema especializada,

No original: (...) un processus morbide qui met le corps en danger. (Nossa tradução).

A figura do flâneur é emblemática para os poetas franceses do final do século 19, principalmente para Charles Baudelaire, conhecido como "o poeta da modernidade", mas, do mesmo modo, como "o último sonhador romântico", título que o próprio Benjamin the consagra em seus ensaios.

0 Antigo Império Khmer dominou todo o sudeste asiático entre os séculos 9 e 15, se estendendo pelo que hoje são o Camboja, Laos, Malásia, Vietnã, além de parte da própria Tailândia. Sua principal religião era o hinduísmo (por influência da Índia e da China, países com os quais mantinha estreitos laços comerciais), mas a cosmologia Khmer é bastante rica, incluindo diversas deidades locais, espíritos ancestrais, fantasmas e seres mágicos, em sua maioria, relacionados a diferentes forças da natureza. 
tendo sido indicado a diversas premiações ${ }^{11}, 0$ que trouxe relativo sucesso ao cineasta. Dois anos depois, aparece Síndromes e um Século (Sang Sattawat, 2006), uma homenagem aos seus pais, com uma narrativa bastante peculiar e fragmentada, mas é mesmo com Tio Boonmee (Uncle Boonmee who can recall his past lifes, 2010) que Joe - como Weerasethakul é conhecido nos Estados Unidos - ganha notoriedade e reconhecimento internacional, sendo agraciado, em 2010, com a Palma de Ouro de melhor filme no Festival de Cinema de Cannes. Seu último filme é Hotel Mekong (Mekong Hotel, 2012), filmado às margens do Rio Mekong, um dos mais importantes afluentes da Tailândia.

Como o próprio nome explicita de partida, $M a l$ dos Trópicos trata de uma "febre repentina" - a paixão amorosa - que acomete dois jovens tailandeses, Keng e Tong, respectivamente, soldado e camponês, homem da lei e homem da natureza. Na dinâmica do filme, os dois amantes assumem posições respectivamente complementares, tal qual os dois polos que compõem sua narrativa. Aos poucos, é como se a carga de erotismo que alimenta a relação vivida entre os rapazes na primeira parte do filme tocasse um limite insuportável, rompendo a própria estrutura da narrativa para revelar uma espécie de metáfora estendida do filme, que traz em cena a mesma história, agora através de um regime expressamente mitológico. Esse novo mundo que aparece inesperadamente frente a nossos olhos incrédulos é o lugar da fantasia (da phantasia ${ }^{12}$ ), espaço habitado por fantasmas e regulado por uma outra lógica, outra racionalidade. Nele, tudo é alternância - luz e sombra, vida e morte, caça e caçador, homem e animal -, revelando um universo regido, essencialmente, pelo signo da ambiguidade.

A ambiguidade, sentimento de estranheza provocado pela manifestação simultânea, em uma mesma unidade, de elementos pertencentes a ordens inversas, contrárias ou incompatíveis entre si, parece mesmo servir como o elemento articulador ${ }^{13}$ central na arquitetura de $\mathrm{Mal}$ dos Trópicos. Nas palavras de seu diretor, o filme "é feito de dois campos magnéticos de um único signo $^{14 ”}$ (WEERASETHAKUL apud Païni, 2010, p.18). No caso, defendemos que a ambiguidade opera como uma espécie de eixo gravitacional

No original: Incarnation technologique (Nossa tradução).

0 cinema tailandês, assim como o de outros países asiáticos (Malásia, Indonésia e Filipinas), recebe forte influência da televisão nacional, com estrelas e astros locais, apresentando uma linguagem bastante padronizada. Para mais informações: http:// www.revistacinetica.com.br/tailandia.htm. Consultado em 06 de março de 2013.

10 Com destaque para Síndromes e um Século, que se passa dentro de um hospital, e Blissfully yours, no qual um dos personagens (o birmanês Min) busca a cura para um misterioso problema de pele que lhe aflige. Em Mal dos Trópicos, poderíamos mencionar a sequência em que Keng e Tong levam a cadela moribunda desse último para o hospital veterinário. 
ao redor do qual o cineasta faz seu filme girar (diz-se rodar um filme), tecendo, com isso, a dupla malha que o reveste. Pois é exatamente a figura controversa do duplo que Weerasethakul escolhe para dar "forma" à sua obra - uma vez que ele a divide em duas narrativas heterogêneas que ressonam enormemente uma na outra -, e, do mesmo modo, manejar seu "conteúdo" - pontuado por um ritmo arrastado e hesitante, fruto do jogo erótico estabelecido pelos dois protagonistas.

Propomos, assim, desenvolver algumas reflexões acerca das ambiguidades presentes em Mal dos Trópicos - mais exatamente sobre a dualidade homem/animal -, estendendo a discussão para 0 estatuto que a imagem cinematográfica assume em relação à experiência do espectador de cinema em nossos dias. Nesse sentido, a obra de Weerasethakul torna-se emblemática para pensarmos o cinema contemporâneo, uma arte em constante transformação, que se abre para a alteridade, para o "devir-outro", revelando, com isso, outras formas de espaço e de temporalidade e outras relações de identidade e de diferença, "criando laços invisíveis e conectando pessoas (espectadores) nessa unidade complexa que é 0 filme" (FRANÇA, 2002, p. 61).

\section{As ambiguidades de Mal dos Trópicos}

0 trabalho de montagem é responsável, em larga medida, pela sensação de ambiguidade que $\mathrm{Mal}$ dos Trópicos desperta e sustenta. É como se cada plano do filme fosse, per se, uma suspensão temporal, uma totalidade que, através de cortes, vem a ser incorporada pelo plano seguinte, pois a necessidade de criar sucessões ou encadeamentos não é um artifício balizador em sua arquitetura. Há de se notar uma "ruptura de tom" (AMIEL, 2007) entre os dois mundos projetados pelo cineasta, que são dialeticamente descontínuos, uma vez que a segunda história não é nem a extensão, nem a antítese da primeira, mas, sim, sua duplicata, um gêmeo quase idêntico; uma sombra, poderíamos dizer.

Enquanto a metade inicial do filme é bastante desdramatizada, sua outra parte, apesar de enfatizar a apreensão sensorial, mostra mais claramente uma conexão entre as cenas, além de incluir a presença de um suposto narrador ${ }^{15}$. A transição acontece por meio de uma "combustão espontânea", por assim dizer: repentinamente, nota-se certa hesitação na película cinematográfica, e a tela é invadida por um clarão, sugerindo algum

Entre elas, o prêmio do júri popular de Cannes e o prêmio da crítica do Festival Internacional de Cinema de São Paulo.

20 termo, oriundo do grego, significa, justamente, aparição.

Para Dominique Païni (2010), colaborador da revista Cahiers du Cinéma, articular o presente a um passado mítico seria a verdadeira obsessão de Weerasethakul. Articulação é ainda o termo escolhido pelo crítico para descrever o estatuto da ficção no cinema do diretor tailandês, equiparando-0, em uma metáfora visual, à figura da dobradiça, que Marcel Duchamps escolhe como símbolo maior para pensar a reversibilidade. 
tipo de problema na projeção do filme ("a ponto de haver assovios para o projecionista", conta 0 crítico Luiz Carlos Oliveira Junior $\left.{ }^{16}\right)$. Somos, então, abandonados na mais completa escuridão por alguns instantes, para, em seguida, adentrarmos em uma nova (mas que ainda é a mesma) narrativa, recontada, agora, em um registro mitológico, no qual homem e animal, vivos e mortos, se hibridizam, tornam-se indistintos.

Adotando Bangcoc e seu ordinário cotidiano como cenário (ainda que muitas sequências se reproduzam no campo), a primeira metade do filme se ocupa em registrar o intenso desejo amoroso que nasce entre dois jovens tailandeses: Tong, um tímido e iletrado camponês, e Keng, um sorridente e popular soldado patrulheiro. Por meio de longos planos-sequência, nós os acompanhamos flanar pela capital tailandesa, envolvidos em atividades bastante corriqueiras: no trabalho ou em casa; no cinema, no karaokê ou no centro comercial; jogando videogame, bilhar ou futebol; rezando em um templo budista ou perscrutando cavernas. Uma insistente morosidade faz com que essas sequências se arrastem de uma a outra, compondo um arranjo de eventos mais ou menos desimportantes; uma sucessão desordenada de imagens cujo vínculo, às vezes, resta um tanto difícil de apanhar. De todo modo, é esse lento - porém constante - fluir da narrativa que garante que o erotismo ganhe corpo, preenchendo cada poro do filme, até atingir um limite do qual, abruptamente, emerge a segunda parte do filme, intitulada "A via do espírito"17".

Com uma nova abertura, o filme renasce, mostrando, em um fade-in, a imagem rupestre de um tigre emoldurando a versão escrita de um conto popular. Era uma vez um poderoso xamã Khmer capaz de se transformar em diversas criaturas. Ele assombrava a floresta e atormentava o vilarejo. Segue-se, então, a cena que ilustra o conto: uma mulher vem pedir ajuda a um soldado, que a acompanha pela floresta a fim de encontrar a mãe da moça, que se encontra enferma. Ao segui-la, o homem percebe uma cauda de tigre sair de seu vestido. Continua 0 conto: Ele matou o tigre e aprisionou o xamã no espírito do felino. Podemos ver a carcaça do tigre no Museu de Kanchanaburid desde então,

No original: (...) est fait de deux champs magnétiques d'un même signe (Nossa tradução).

15 Lembremos que a segunda parte do filme começa com a apresentação de um conto, introduzido por uma voz em off, que volta a intervir na narrativa em outros momentos (notadamente, na cena em que Tong, na floresta, ao encarnar o xamã, rouba os pertences do soldado).

16 Em: www.contracampo.com.br/64/tropicalmalady.htm. Consultado em 13 de fevereiro de 2014.

17 Essa segunda parte do filme é inspirada em uma série de trabalhos do romancista tailandês Noi Inthanon, que escreve histórias sobre a floresta tropical. 
e, a cada noite, o xamã encarna num tigre $e$ amedronta os viajantes. No vilarejo, homens $e$ animais começaram a desaparecer.

Nessa outra parte, Weerasethakul abandona a cidade para, de maneira obstinada, acompanhar Keng floresta adentro em busca do tigre/xamã que vem assustando os moradores das redondezas. A hesitação, que já pontuava a primeira parte do filme, parece aqui se intensificar ainda mais, fazendo com que os limites entre caça e caçador se tornem indefinidos e incertos, até se perderem por completo. Ao penetrar a selva tropical, o filme se transforma em uma intensa experiência sensorial, encenada por meio de uma fábula cambojana que o cineasta recobre, como já mencionamos, com os predicados de uma narrativa mitológica.

É notável, por exemplo, a montagem alternada entre 0 rosto do homem e a cara do tigre que, intervaladas, perfazem a sequência final do filme.
A penumbra da floresta e a pouca iluminação fixada na altura dos olhos -, além da ausência de uma trilha sonora, são elementos que ajudam a compor 0 suspense que a cena carrega. Nela, Keng e 0 animal são registrados em primeiro plano, simetricamente posicionados em relação à câmera (tanto em angulação, quanto em distanciamento), desafiando o espectador a participar desse "duelo de olhares", ora encarando o soldado, ora 0 tigre (figuras 1 e 2). Aos olhos impenetráveis do animal, se opõem 0 medo e 0 desejo que os olhos marejados do soldado deixam desvelar. Explicita-se aqui uma proposital triangulação provocada por esse jogo especular e conquistada através da inclusão de um terceiro olhar, que hesita entre dois pontos de certa forma incompatíveis - mas, paradoxalmente, complementares -, e que serve tanto de garantia para a instabilidade que atravessa a narrativa, quanto de testemunha para 0 embate final entre 0 homem e 0 animal: 0 olhar do espectador.

Figura 1: 0 soldado encara a câmera/o tigre.

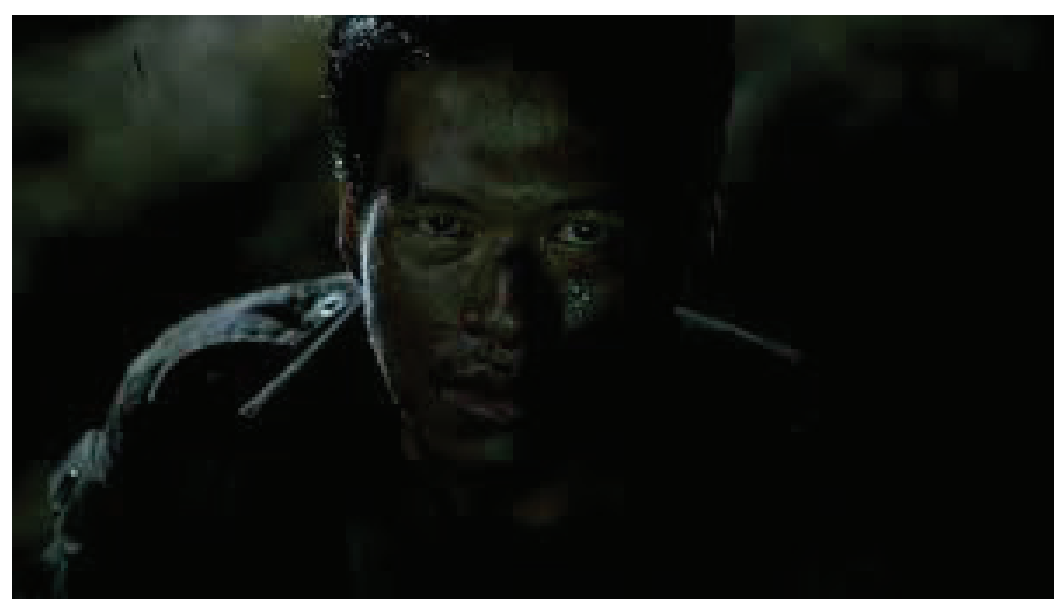

Imagens extraídas do filme Mal dos Trópicos. 
Figura 2: 0 tigre devolve 0 olhar para 0 soldado/ a câmera.

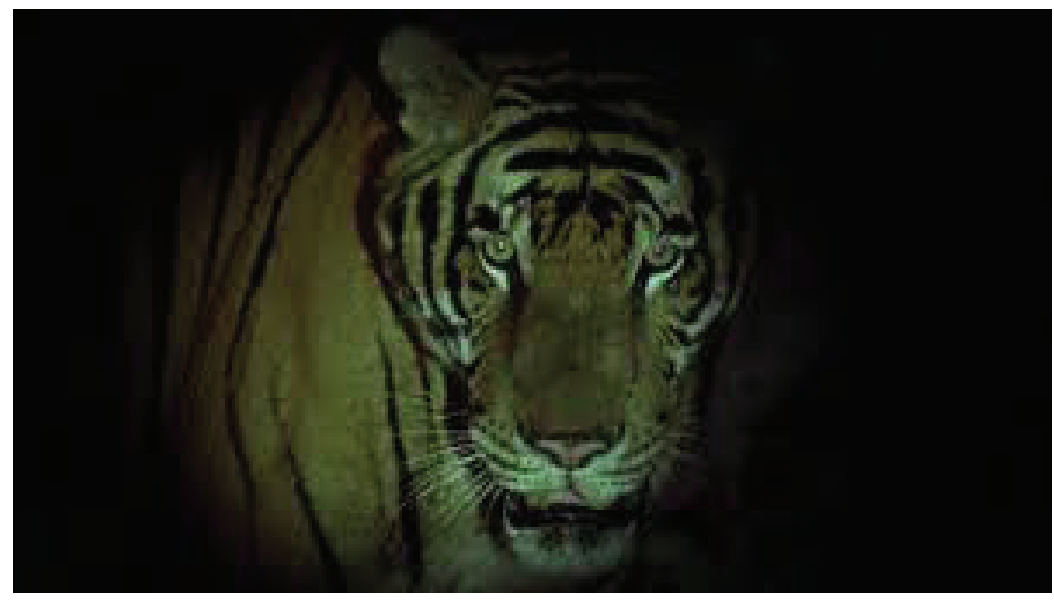

Imagens extraídas do filme Mal dos Trópicos.

Todos nós somos bestas selvagens. Nosso dever como seres humanos é o de nos tornarmos como domadores, que mantêm seus animais nas jaulas, lhes ensinando a desenvolver tarefas alheias à sua bestialidade. Se essa frase do escritor japonês Ton Nakajima é escolhida por Weerasethakul como epígrafe para Mal dos Trópicos, é porque ela sintetiza o infindável conflito entre a razão e 0 instinto - ou entre as ordens cultural e o natural -, revelando, com isso, a submissão de uma ordem à outra. Domar a agressividade - a bestialidade - parece mesmo ser 0 grande desafio da civilização, uma vez que a relação entre homem e animal ocorre de maneira transversal, como defende Benedito Nunes (2007), "ou seja, 0 animal é considerado o oposto do homem, mas, ao mesmo tempo, uma espécie de simbolização do próprio homem $^{18 "}$ (NUNES, 2007).

Com o cristianismo, os antigos deuses pagãos - muitos deles representados de maneira antropomórfica - foram demonizados ou tiveram de migrar "para o mais fundo da alma", e 0 animal passa a ser símbolo do "irascível dos sentimentos e da bruteza dos instintos" (NUNES, 2007).

Através da consubstanciação entre as noções de pensamento e consciência promovida pelo pensamento cartesiano, homem e animal tornamse seres cada vez mais estranhos um ao outro. As feridas narcísicas provocadas por Copérnico - que nos retira do centro do universo - e por Darwin - que nos coloca no topo de uma cadeia evolutiva - geram um embaraço ainda mais grave, diz Nunes. Assim, até hoje, "0 animal continua sendo esse grande Outro, o maior alienado de nossa cultura", que parece não oferecer mais nenhuma possibilidade de "reestabelecer os estreitos laços que nos uniam nos tempos mitológicos" (NUNES, 2007). As palavras de Nakajima comporiam, nesse sentido, uma metáfora da domesticação de nossas 
paixões em nome de um pretenso desenvolvimento cultural, deixando à mostra a dialética entre Eros e Thanatos, essas duas forças pulsionais que nos estruturam e às quais obedecem nossas ações.

Assim, distinguimos em Mal dos Trópicos um duplo movimento de transformação. Em um primeiro momento, sublinhamos a personificação do tigre sob a forma do xamã, encarnado na figura de Tong. Vemos o moço correr nu pela floresta, com o corpo todo pintado, tal como fazem os ameríndios, mas agindo como um animal selvagem, atacando seu adversário e lhe roubando suas ferramentas. 0 soldado, por sua vez, vai perdendo seus atributos humanos e civilizadores (não apenas a mochila, o rádio e a comida, mas, do mesmo modo, a voz e a razão), tornando-se, gradativamente, parte integrante da selva que o envolve. É somente ao desistir de sua condição de bípede, ao cair de quatro no solo e por ele engatinhar, que o soldado consegue, finalmente, encontrar sua presa (ainda que não se saiba, nessa altura, quem é realmente caça ou caçador). 0 filme mostra, portanto, não apenas uma humanização dos animais - como o primata que avisa Keng da proximidade do tigre, 0 espírito da vaca que deixa sua carcaça morta, ou, ainda, o próprio tigre, que transmite seus pensamentos ao soldado, momentos antes de devorá-lo - mas, igualmente, uma animalização do homem, 0 que embaralha bastante qualquer tentativa de diferenciação ou de identificação mais rígida ou determinista entre essas duas categorias. Nesse caso, parece que "é a troca e não a identidade, 0 valor fundamental a ser afirmado" (CLIFFORD apud VIVEIROS DE CASTRO, 2002, p. 206).

Através da ideia do perspectivismo, elaborada e defendida por Eduardo Viveiros de Castro (2002), o homem branco se distingue dos outros animais, mas não deixa de partilhar com eles uma mesma origem biogenética, um mesmo "fundo biológico", por assim dizer. A ideia, nesse caso, é a de que a cultura seria, metaforicamente, uma espécie de invólucro, uma roupagem que, uma vez retirada, abandonada, mostraria a desnudada verdade de que não passamos de animais (ainda que domesticados). No entanto, a cosmologia ameríndia vem pressupor um estado primordial da vida, no qual todos os seres vivos transitariam por variadas formas antes de, finalmente, se fixarem em uma delas. Assim, ao contrário dos homens brancos, esses povos acreditam que, de fato, é o corpo animal que teria esse caráter indumentário, escondendo um fundo humano, uma essência humana; uma alma humana que atravessa todos os seres. Isso significa dizer que é a condição humana e não a natureza animal que vem preencher e significar todos os seres do mundo, transformando cada espécie em um distinto centro de consciência.

Ainda considerando a relação entre natureza e cultura, o perspectivismo oferece uma visão multinaturalista (uma cultura, variadas naturezas), em contrapartida a uma postura multiculturalista (uma natureza, diversas 
culturas), conduzida pelo relativismo cultural. Ao tomar o próprio corpo como o elemento que diferencia os animais entre si e o homem - uma corporeidade não mais pensada como uma construção biológica, mas, sim, como algo construído ao longo da vida e por meio das relações sociais -, o perspectivismo coloca em questão as noções de sujeito e de substância, privilegiando o caráter relacional da realidade e abandonando a concepção de um mundo dado a priori. Isso faz com que 0 xamanismo - ou, mais precisamente, a figura do xamã - ganhe destaque nesse contexto. Conhecido como a "técnica do êxtase" (ELIADE, 1998), o xamanismo se refere à capacidade que possuem certos humanos de "cruzar barreiras corporais e adotar a perspectiva de subjetividades não-humanas" (VIVEIROS DE CASTRO, 2002, p.468). Essa dita "função xamânica" estaria associada àquilo que 0 autor chama de "interioridade social de natureza substantiva" (VIVEIROS DE CASTRO, 2002, p. 471), isto é, ao surgimento de valores tais como a ancestralidade (marcada pela ideia de uma continuidade diacrônica entre os vivos e os mortos) e a hierarquia (por sua vez, marcada pela descontinuidade sincrônica entre vivos).

Marie-José Mondzain ${ }^{19}$ explica que os dispositivos ficcionais nos quais se inscrevem as metamorfoses - entre os quais o cinema tem um papel preponderante - têm a ver com a miseen-scène de uma angústia. Sua resolução ocorre por meio de uma estratégia de logros, astúcias e deslocamentos que 0 estatuto "mutante" da imagem possibilita. "A metamorfose oferece a variação infinita das substituições e das mudanças. (...) 0 apagamento da subjetividade é 0 verdadeiro sentido da metamorfose" (MONDZAIN, 2010, p. 189). A filósofa reconhece na imagem uma função xamânica, na medida em que ela também traria em si mesma a possibilidade de despertar tais regimes temporais relacionados ao mito, efetuando uma profunda transformação de ordem subjetiva. Segundo ela, há, na imagem, uma "energia sísmica, que faz com que tudo troque de lugar, que tudo ganhe outro regime de consciência”"20. De fato, a figura do xamã e 0 artifício da metamorfose nos parecem fundamentais para pensarmos um tipo de arte que possibilite a produção da alteridade por meio da semelhança e vice-versa (LAGROU, 2007).

Para os índios Kaxinawa, como explica a antropóloga Els Lagrou (2007), o dualismo se reverteria em um meio para se tornar um ao invés de dois - simultaneamente "0 mesmo" e "outro" -, destacando, com isso, o caráter posicional, relativo e temporal de nossa visão de mundo; lugar onde as identidades não são mais essenciais, substanciais ou fixas, 
mas, ao contrário, flexíveis e fluidas. Assim, a diferença deixa de estar localizada no registro da oposição, passando a ser gradual. Uma pretensa consciência de interdependência dos seres vivos estaria implícita, ressaltando como as relações entre o eu e o outro podem ser muito mais complexas e relativas, com fronteiras menos rígidas e muito mais moventes.

No caso de Mal dos Trópicos, a relação entre identidade e diferença se torna, com efeito, demasiadamente imbricada. Basta pensarmos, por exemplo, que o tigre, segundo o conto Khmer cuja encenação serve para introduzir a segunda parte do filme, toma inicialmente 0 corpo/a forma de uma mulher. 0 caçador, ao lhe identificar a cauda saindo pelo vestido, mata a fera, aprisionando o xamã no espírito do animal. 0 xamã decide então se vingar, se transmutando em tigre para, durante a noite, vir assombrar os moradores do vilarejo. Logo, 0 tigre ganha duas animas: a do xamã aprisionado, além da sua própria. Simultaneamente, nas cenas registradas durante 0 dia, a alma do felino parece se incorporar na figura de Tong, que corre nu pela selva, com o corpo marcado por inscrições e desenhos. E lembremos ainda que, ao devorar o soldado, esse mesmo tigre se apodera da alma de Keng, se tornando, por conseguinte, também 0 soldado, desdobramentos que fazem com que as reflexões de Lagrou, mencionadas anteriormente, ganhem algum sentido.

0 caçador pode se tornar caça, parentes podem se tornar estranhos ou outros seres, e estranhos ou inimigos podem se tornar repre- sentantes do ser mais próprio e do que é mais valorizado pela comunidade dos humanos. Uma consciência da interdependência dos seres vivos é traduzida por uma cosmologia que coloca os processos de transformação no centro da reflexão. A questão do significado da semelhança e da diferença, antes um problema classificatório, passa a ser um paradoxo filosófico. (LAGROU, 2007, p. 535)

0 itinerário de Keng pela floresta é, a um só tempo, físico e mental, psicológico e místico (SCHEINFEIGEL, 2008, p.155). A migração entre universos, vivida como entrega e assimilação, destitui os lugares rígidos, enfatizando a relação de alteridade e 0 intercâmbio de identidades. A fricção de dois universos tão distintos, mas, paradoxalmente, tão próximos um do outro, faz emergir um tempo mítico, um mundo imaginário, no qual os homens e os animais falam uma mesma língua, uma língua universal, por assim dizer. Nessa perspectiva, Lagrou (2007) lembra que, na construção/constituição da pessoa ameríndia, a ideia de incorporação do outro é incontornável, acontecendo por meio do acúmulo ao invés da divisão. A possibilidade de se metamorfosear em outros seres é algo nuclear para esse tipo de sociedade, baseada, até certo ponto, na "luta pelo controle da forma" (LAGROU, 2007, p.28), que aparece sempre condicionada por uma fluidez e por um devir outro. Para esses grupos, a pessoa é sempre concebida como um ser relacional, processual e divisível, tendo em vista que "partes de si que passam para outras pessoas continuam mantendo relação com a pessoa que as emitiu, 
ao mesmo tempo que ajudam a produzir novos seres" (LAGROU, 2007, p.26).

Ecoa, aqui, o conto de Guimarães Rosa "Meu Tio o Iauaretê" (1961), que narra a história de um mestiço de índios e brancos, caçador de bichos, e seu destino exemplar, ao transformar-se em onça, matadora de homens. Walnice Nogueira Galvão (1978) relaciona o felino a um dos mitos Kayapó, no qual a onça é Senhor do fogo. Buscando a oposição apresentada por LéviStrauss em seu livro O Cru e o Cozido, Galvão explica: "Se o matador de onças se identifica com ela [a onça] e se torna matador de homens - e está coberto de razão - a rejeição do mundo civilizado, domínio do cozido, é acompanhada pela volta ao mundo da natureza, domínio do cru" (GALVÃO, 1978, p.13). A estrutura do conto, assim como a narrativa do filme de Weerasethakul, é trabalhada formalmente (por meio de travessões) no sentido de transformar a voz do narrador e de seu interlocutor em uma única voz, fazendo com que a enunciação flua ininterruptamente da boca de um narrador que é, de fato, o outro. "0 narrador tem sua alteridade marcada com relação ao interlocutor. (...) 0 interlocutor nunca fala, mas é colocado na fala do outro por meio das interpelações e respostas a hipotéticas perguntas" (GALVÃO, 1978, p.34).

Se Mal dos Trópicos é composto de dois mundos, é somente pela dessemelhança que eles podem incidir um sobre o outro; pois é nela e através dela que a alteridade pode manifestar-se. Um primeiro mundo, com elementos da realidade e organizado pela lógica, dá lugar a um segundo universo, aparentemente desconhecido, que não mais responde a um entendimento da ordem do racional, abandonado em nome de uma experiência quase mística. Ao colocar em cena nossos medos e nossos desejos - elementos que designam, com frequência, as próprias sombras que nos habitam -, o cinema enforma, enquadra e encena a vida, tentando, de algum modo, dar sentido à morte. Como infere Mondzain (2010, p.82), nenhuma cultura encontra consistência fora da relação entre os vivos e os mortos e a imagem. E se o visível sempre pressupõe a presença do outro - ou, dito de outro modo, se "toda imagem deseja a alteridade ${ }^{21 "}$ (NANCY apud ALLOA, 2010, p.75) -, é em direção ao espectador que ela projeta esse pretenso desejo.

\section{Considerações Finais}

Em seu filme, Weerasethakul se serve desse desdobramento como uma "estratégia discursiva", por assim dizer, no intuito de apanhar seu espectador e, com isso, conquistar sua instabilidade, garantida, como tentamos mostrar, por meio da sensação de ambiguidade gerada pelo friccionar das duas histórias filmadas que, em interação, compõem a estrutura fragmentada da obra. Na verdade, o espectador é lançado no limiar desses dois supostos universos, nesse espaço 
intermediário, no qual nada é fixo, mas tudo é mutante; se encontra em perpétua transformação.

Essa transição de mundos designa, quiçá, o estado de enamoramento, o sentimento da paixão que promove no sujeito uma intensa identificação com 0 objeto, um desejo de fusão. Em nome desse desejo, a narrativa então se fragmenta para ganhar um outro rumo e encontrar seu duplo mitológico. A intensidade da paixão provoca um retorno às trevas fusionais que habitam o sujeito; algo de fantasmático se revela e é encenado sob a forma de uma narrativa iniciática. Assim, no filme de Weerasethakul, "a animalidade xamânica é convocada e a presença da morte e dos fantasmas associa-se ao apetite bestial do desejo" (MONDZAIN, 2010, p. 182).

Talvez o desejo do cineasta seja mesmo o de se estender no tempo e no espaço da cena filmada, a fim de nela capturar o momento exato de uma transformação, 0 instante preciso no qual uma fratura viria a se abrir, rompendo, assim, o véu que separa o mundo de seu duplo. Esses dois registros (o dos vivos e 0 dos mortos/do homem e dos animais?) se tocam, se esbarram; flertam 0 tempo todo um com 0 outro, se perseguem mutuamente até se incorporarem por completo, tal como 0 tigre devora a alma do soldado. Desse modo, entre homens e animais, corpos e espectros, vivos e mortos, uma certa instabilidade surge para, como umfantasma, atravessar toda a obra e vir também a assombrar, em maior ou menor medida, a relação que 0 espectador estabelece com 0 filme.

\section{Referências}

ALLOA, Emmanuel (ed.) Penser l'image. Paris: Les presses du réel, 2010.

AMIEL, Vincent. A Estética da Montagem. Lisboa: Texto e Grafia, 2007.

COMOLLI, Jean-Louis. Ver e Poder. Belo Horizonte: UFMG, 2008.

ELIADE, Mircea. Xamanismo e as Técnicas Arcaicas do Êxtase. São Paulo: Martins Fontes, 2002.

FRANÇA, Andréa. Paisagens fronteiriças no cinema contemporâneo. Revista ALCEU, v. 2, n. 4. Rio de Janeiro: Editora PUC-Rio, jan.jun. 2002, pp. 61-75.

GALVÃo, Walnice Nogueira. Mitológica Roseana. São Paulo: Ática, 1978.

LAGROU, Els. A fluidez da forma: arte, alteridade e agência em uma sociedade amazônica (Kaxinawa, Acre), Rio de Janeiro: Top Books, 2007.

MONDZAIN, Marie-José. A perseguição no cinema: um ensaio sobre Mal dos Trópicos, de Apichatpong Weerasethakul. Revista Devires, Cinema e Humanidades, Belo Horizonte, V.7, n. 2, Jul/Dez 2010 (b), pp. 180/197.

. Images (à suivre). De la poursuite au cinéma et ailleurs. Paris: Bayard, 2011.

NUNES, Benedito. 0 animal e o primitivo: os Outros de nossa cultura. Rio de Janeiro, v. 14, suplemento, dez.2007. p. 279-290.

PAÏNI, Dominique. Cinq Cinéastes pour les années 2000. Revista Cahiers du Cinéma, n. 6752, Janvier 2010. pp.18-23.

ROSA, Guimarães. "Meu tio o Iauaretê" In:

Estas estórias. $3^{\mathrm{a}}$ ed. Rio de Janeiro: Nova Fronteira, 1985. p. 176.

SCHEINFEIGEL, Maxime. Cinéma et magie. Paris: Armand Colin Cinéma, 2008. 
VIEIRA JR., Erly. 0 tempo dos corpos no "cinema de fluxo" de Apichatpong Weerasethakul. Intercom - Sociedade Brasileira de Estudos Interdisciplinares da Comunicação. In XXXII Congresso Brasileiro de Ciências da Comunicação - Curitiba, PR - 4 a 7 de setembro de 2009.

VIVEIROS DE CASTRO, Eduardo. A Inconsistência da alma selvagem e outros ensaios de antropologia.

São Paulo: Cosac Naify, 2002. 
The Ambiguity human/animal in Tropical Malady and the Shamanic dimension of Image

\section{La ambigüedad hombre/animal en Tropical Malady y la dimensión chamánica de la Imagen}

\section{Resumen}

En este artigo proponemos desarrollar algunas refecciones acerca de las ambigüedades presentes en la película tailandesa Tropical Malady - más precisamente en lo tocante a la dualidad hombre/ animal - extendiendo la discusión para pensar el estatuto de la imagen cinematográfica en nuestros días y su relación con el espectador contemporáneo. El trabajo de Weerasethakul es ejemplar para reflexionar sobre el cine contemporáneo, un arte en perpetua transformación, abierto a la alteridad, indicando, de esta manera, otros espacios y otras temporalidades así como también nuevas relaciones entre la identidad y la diferencia.

\section{Palabras-Clave}

Cine. Weerasethakul. Ambigüedad. Imagen. Alteridad. 


\section{Expediente}

A revista E-Compós é a publicação científica em formato eletrônico da Associação Nacional dos Programas de Pós-Graduação em Comunicação (Compós). Lançada em 2004, tem como principal finalidade difundir a produção acadêmica de pesquisadores da área de Comunicação, inseridos em instituições do Brasil e do exterior.

\section{E-COMPÓS I www.e-compos.org.br I E-ISSN 1808-2599}

Revista da Associação Nacional dos Programas

de Pós-Graduação em Comunicacão.

Brasília, v.17, n.3, set./dez. 2014

A identificação das edições, a partir de 2008

passa a ser volume anual com três números.

\section{CONSELHO EDITORIAL}

Afonso Albuquerque, Universidade Federal Fluminense, Brasil Alberto Carlos Augusto Klein, Universidade Estadual de Londrina, Brasil Alex Fernando Teixeira Primo, Universidade Federal do Rio Grande do Sul, Brasil Rio Grande do Sul, Brasi

Ana Gruszynski, Universidade Federal do Rio Grande do Sul, Brasil Ana Silvia Lopes Davi Médola, Universidade Estadual Paulista, Brasil André Luiz Martins Lemos, Universidade Federal da Bahia, Brasi Ângela Freire Prysthon, Universidade Federal de Pernambuco, Brasil Antônio Fausto Neto, Universidade do Vale do Rio dos Sinos, Brasil Antonio Carlos Hohlfeldt, Pontifícia Universidade Católica do Rio Grande do Sul, Brasil Antonio Roberto Chiachiri Filho, Faculdade Cásper Líbero, Brasi Arlindo Ribeiro Machado, Universidade de São Paulo, Brasil Arthur Autran Franco de Sá Neto, Universidade Federal de São Carlos, Brasil Benjamim Picado, Universidade Federal Fluminense, Brasil César Geraldo Guimarães, Universidade Federal de Minas Gerais, Brasil Cristiane Freitas Gutfreind, Pontifícia Universidade Católica do Rio Grande do Sul, Brasil Denilson Lopes, Universidade Federal do Rio de Janeiro, Brasil Denize Correa Araujo, Universidade Tuiuti do Paraná, Brasil Edilson Cazeloto, Universidade Paulista, Brasil

Eduardo Vicente, Universidade de São Paulo, Brasil

Eneus Trindade, Universidade de São Paulo, Brasil

Erick Felinto de Oliveira, Universidade do Estado do Rio de Janeiro, Brasil Florence Dravet, Universidade Católica de Brasilia, Brasil

Gelson Santana, Universidade Anhembi/Morumbi, Brasi Gilson Vieira Monteiro, Universidade Federal do Amazonas, Brasil Gislene da Silva, Universidade Federal de Santa Catarina, Brasil Guillermo Orozco Gómez, Universidad de Guadalajara, México Gustavo Daudt Fischer, Universidade do Vale do Rio dos Sinos, Brasil Hector Ospina, Universidad de Manizales, Colômbia Herom Vargas, Universidade Municipal de São Caetano do Sul, Brasil leda Tucherman, Universidade Federal do Rio de Janeiro, Brasil Inês Vitorino, Universidade Federal do Ceará, Brasil Janice Caiafa, Universidade Federal do Rio de Janeiro, Brasil Jay David Bolter, Georgia Institute of Technology, Estados Unidos Jeder Silveira Janotti Junior, Universidade Federal de Pernambuco, Brasi João Freire Filho, Universidade Federal do Rio de Janeiro, Brasil John DH Downing, University of Texas at Austin, Estados Unidos Ana Carolina Damboriarena Escosteguy, Pontifícia Universidade Católica do

José Afonso da Silva Junior, Universidade Federal de Pernambuco, Brasil José Carlos Rodrigues, Pontifícia Universidade Católica do Rio de Janeiro, Brasil José Luiz Aidar Prado, Pontifícia Universidade Católica de São Paulo, Brasil José Luiz Warren Jardim Gomes Braga, Universidade do Vale do Rio dos Sinos, Brasil Juremir Machado da Silva, Pontifícia Universidade Católica do Rio Grande do Sul, Brasil Laan Mendes Barros, Universidade Metodista de São Paulo, Brasi Lance Strate, Fordham University, USA, Estados Unidos Lorraine Leu, University of Bristol, Grã-Bretanha Lucia Leão, Pontifícia Universidade Católica de São Paulo, Brasil Luciana Panke, Universidade Federal do Paraná, Brasil Luiz Claudio Martino, Universidade de Brasília, Brasil Malena Segura Contrera, Universidade Paulista, Brasil Márcio de Vasconcellos Serelle, Pontifícia Universidade Católica de Minas Gerais, Brasil Maria Aparecida Baccega, Universidade de São Paulo e Escola Superior de Propaganda e Marketing, Brasi Maria das Graças Pinto Coelho, Universidade Federal do Rio Grande do Norte, Brasil Maria Immacolata Vassallo de Lopes, Universidade de São Paulo, Brasil Maria Luiza Martins de Mendonça, Universidade Federal de Goiás, Brasil Mauro de Souza Ventura, Universidade Estadual Paulista, Brasil Mauro Pereira Porto, Tulane University, Estados Unidos Nilda Aparecida Jacks, Universidade Federal do Rio Grande do Sul, Brasil Paulo Roberto Gibaldi Vaz, Universidade Federal do Rio de Janeiro, Brasil Potiguara Mendes Silveira Jr, Universidade Federal de Juiz de Fora, Brasil Renato Cordeiro Gomes, Pontifícia Universidade Católica do Rio de Janeiro, Brasil Robert K Logan, University of Toronto, Canadá

Ronaldo George Helal, Universidade do Estado do Rio de Janeiro, Brasil Rosana de Lima Soares, Universidade de São Paulo, Brasi Rose Melo Rocha, Escola Superior de Propaganda e Marketing, Brasil Rossana Reguillo, Instituto de Estudos Superiores do Ocidente, México Rousiley Celi Moreira Maia, Universidade Federal de Minas Gerais, Brasi Sebastião Carlos de Morais Squirra, Universidade Metodista de São Paulo, Brasil Sebastião Guilherme Albano da Costa, Universidade Federal do Rio Grande do Norte, Brasil

Simone Maria Andrade Pereira de Sá, Universidade Federal Fluminense, Brasi Suzete Venturelli, Universidade de Brasília, Brasil

Tiago Quiroga Fausto Neto, Universidade de Brasília, Brasil

Valerio Fuenzalida Fernández, Puc-Chile, Chile

Veneza Mayora Ronsini, Universidade Federal de Santa Maria, Brasi Vera Regina Veiga França, Universidade Federal de Minas Gerais, Brasil

\section{COMISSÃO EDITORIAL}

Cristiane Freitas Gutfreind I Pontifícia Universidade Católica do Rio Grande do Sul, Brasil Irene Machado I Universidade de São Paulo, Brasil

Jorge Cardoso Filho I Universidade Federal do Recôncavo da Bahia, Brasil Universidade Federal da Bahia, Brasil

CONSULTORES AD HOC

Adriana Amaral, Universidade do Vale do Rio dos Sinos, Brasil

Alexandre Rocha da Silva, Universidade Federal do Rio Grande do Sul, Brasi

Arthur Ituassu, Pontifícia Universidade Católica do Rio de Janeiro, Brasil

Bruno Souza Leal, Universidade Federal de Minas Gerais, Brasil

Elizabeth Bastos Duarte, Universidade Federal de Santa Maria, Brasil

Francisco Paulo Jamil Marques, Universidade Federal do Ceará, Brasi

Maurício Lissovsky, Universidade Federal do Rio de Janeiro, Brasil

Suzana Kilpp, Universidade do Vale do Rio dos Sinos, Brasil

Vander Casaqui, Escola Superior de Propaganda e Marketing, Brasi

EDIÇ̃̃O DE TEXTO E RESUMOS I Press Revisão

SECRETÁRIA EXECUTIVA I Helena Stigger

EDITORAÇÃo ELETRÔNICA I Roka Estúdio
COMPÓS I www.compos.org.br

Associação Nacional dos Programas de Pós-Graduação em Comunicação

Presidente

Eduardo Morettin

Universidade de São Paulo, Brasil

eduardomorettin@usp.br

Vice-presidente

Inês Vitorino

Universidade Federal do Ceará, Brasil

ines@ufc.br

Secretária-Geral

Gislene da Silva

Universidade Federal de Santa Catarina, Brasil

gislenedasilva@gmail.com 